\title{
A RELAÇÃO TRABALHO E EDUCAÇÃo NA PEDAGOGIA DA ALTERNÂNCIA
}

\author{
Glademir Alves Trindade \\ glademir.trindade@gmail.com \\ Universidade Tecnológica Federal do Paraná - UTFP \\ Célia Regina Vendramini \\ celiavendram@gmail.com \\ Universidade Federal de Santa Catarina - UFSC
}

\section{RESUMO}

No projeto educativo em curso na Pedagogia da Alternância, a relação entre trabalho e educação aparece como alternativa para os jovens do campo. Enquanto projeto educativo, consideramos tal articulação fundamental para a constituição de um projeto de educação emancipatório. No que se refere à proposição da Pedagogia da Alternância, objetivamos analisar como se estabelece a relação trabalho e educação no âmbito da concepção educativa desta pedagogia, identificando seus limites e possibilidades na direção de uma educação para além do capital. Para tal discussão, lançamos mão das categorias de trabalho, como categoria central no processo de constituição do ser humano e de educação como mediadora deste processo.

Palavras-Chave: Trabalho; Educação e Pedagogia da Alternância.

\section{THE RELATION BETWEEN WORK AND EDUCATION IN THE PEDAGOGY OF ALTERNATION}

\begin{abstract}
In a Pedagogy of Alternation present educating project, the relation between work and education emerges as an alternative to the countryside youngsters. As an educating project, we consider this articulation crucial to the constitution of an emancipating educational project. In relation to the proposition of the Pedagogy of Alternation, we have the aim of analyzing how the relation between work and education is established in the field of the educating conception of this pedagogy, identifying its limits and possibilities towards a beyond capital education. For such discussion, we have used the categories of work, as a central category in the process of human being constitution, and of the education as a mediator of this process.
\end{abstract}

Keywords: Work, Education and Pedagogy of Alternation.

\section{Introdução}

A Pedagogia da Alternância é uma modalidade de organização do ensino escolar que consiste na articulação de diferentes experiências formativas distribuídas ao longo de tempos e espaços distintos, tendo como foco a formação profissional. Os espaços dizem respeito aos locais onde a formação se processa, como por exemplo, a escola e a propriedade agrícola. Os tempos dizem respeito aos períodos de permanência dos educandos nesses espaços, nos quais são desenvolvidas atividades educativas previamente planejadas e orientadas em sua execução. Dessa forma após um período de permanência na escola, que pode ser de uma semana a quinze dias em regime de internato, sobrevém um período equivalente de permanência na família trabalhando na propriedade, daí a alternância. 
No que diz respeito à origem, a Pedagogia da Alternância começou a tomar forma no ano de 1935, em Lot-et-Garone, região Sudoeste da França, a partir das insatisfações de um pequeno grupo de agricultores com o sistema educacional de seu pais, o qual não atendia, a seu ver, as especificidades de uma educação para o meio rural (GIMONET, 1999). Em geral, os interesses desse grupo enfatizavam a necessidade de uma educação escolar que atendesse as especificidades psicossociais dos adolescentes e que também propiciasse, alem da profissionalização, elementos para o desenvolvimento social e econômico da sua região.

Por se tratar de uma experiência, que parece extrapolar o âmbito da escola tradicional a partir do momento que insere o trabalho no processo pedagógico, procuramos analisar aqui como ocorre a relação entre trabalho e educação e discutir as possibilidades e limites da alternância. Pois entendemos que estão postos aí dois elementos - trabalho e educação - fundamentais, para construir um projeto que contemple a superação da atual relação capital-trabalho.

\section{A alternância trabalho e educação}

Já é notório que a divisão do trabalho introduzida pela maquinaria e grande indústria provocou mudanças tanto nos processos de produção, quanto nos processos de aprendizagem ao exigir em termos educativos um novo tipo de disciplinamento do trabalhador e novos modos de vida, comportamento, atitudes e valores o que caracteriza a educação como um processo social, historicamente determinado e determinante. A aprendizagem há muito não acontece apenas pela experiência, fazendo, observando, como nos processos pré-industriais Esta questão foi levantada por Marx e Engels, quando escreveram no Manifesto:

E vossa educação não é também determinada pela sociedade? Pelas condições sociais em que educais vossos filhos, pela intervenção direta ou indireta da sociedade, por meio de vossas escolas etc.? Os comunistas não inventaram a intromissão da sociedade na educação; apenas procuraram modificar seu caráter arrancando a educação da influência da classe dominante (MARX e ENGELS, 2007, p.55).

Diz Mészáros a este propósito que "os processos educacionais e os processos sociais mais abrangentes de reprodução estão intimamente ligados" (MÉSZÁROS, 2007, p. 245). A educação expressa assim as contradições e a própria sociedade em que está inserida de tal forma que os limites e possibilidades da mesma estão circunscritos aos limites e possibilidades da sociedade que a produz. Isso significa que lutar por educação é lutar simultaneamente pela transformação da sociedade, pois "o apelo para que abandonem as ilusões a respeito da sua condição é o apelo para abandonarem uma condição que precisa de ilusões" (MARX, 2005, p. 145).

Tendo em vista que o fundamento da sociedade industrial é a divisão do trabalho e por extensão do trabalhador, a educação neste contexto acontece de forma fragmentada. Assim temos, neste caso, a fragmentação entre o conhecimento científico e o saber prático, pois para competir (competência) não é mais necessário articular teoria e prática, já a práxis histórica, esta atividade produtiva e especificamente humana, esta sim, pressupõe a articulação entre saber cientifico e prático (VÁZQUEZ, 2007). Por isso, Vázquez nos alerta a este respeito para a necessidade de buscar a superação desta fragmentação.

A teoria em si [...] não transforma o mundo. Pode contribuir para a sua transformação, mas por isso tem de sair de si mesma e, em primeiro lugar, tem de ser assimilada pelos que hão de suscitar, com seus atos 
reais, efetivos, essa transformação. Entre a teoria e a atividade prática transformadora se insere um trabalho de educação das consciências, de organização dos meios materiais e planos concretos de ação; tudo isso como passo indispensável para desenvolver ações reais efetivas. Nesse sentido, uma teoria é pratica quando materializa, por meio de uma série de mediações, o que antes só existia idealmente, como conhecimento da realidade ou antecipação ideal de sua transformação (VÁZQUEZ, 2007, p. 235-236).

Portanto, conceber a educação como uma dimensão essencial no processo histórico e constitutivo do ser humano, é fundamental para entender a função da educação na sociedade de classes. É essencial também para a classe trabalhadora construir o seu projeto educativo na perspectiva emancipatória tomando por base a formação omnilateral ${ }^{1}$ que faça o contraponto à educação capitalista e sua formação fragmentada e cada vez mais tecnicista - unilateral.

Parece não restar dúvidas que a educação na sociedade capitalista passa a cumprir duas funções básicas para implementar a lógica do capital que é a produção ampliada de valor, assim configuradas: “(1) a produção das qualificações necessárias ao funcionamento da economia e (2) a formação dos quadros e a elaboração dos métodos de controle político" (MÉSZÁROS, 2006, p.275). Logo, a educação correspondente a essa sociedade que tem na divisão do trabalho um meio de se reproduzir e se perpetuar, caracteriza-se como uma educação voltada para a adequação do indivíduo ao meio. Por isso nos alerta Suchodolski ao fazer a crítica da pedagogia baseada na essência do homem que: "se a educação do indivíduo é o resultado da ação do ambiente, então a adequação é o verdadeiro conteúdo da educação, concluem os reacionários do sensualismo" (1976, p.162), ou seja, para a burguesia a educação deve mediar a adequação ao meio e não a transformação deste. No entanto, diz Suchodolski: "se a educação do indivíduo é o resultado da ação do meio ambiente, então este ambiente deve ser transformado pelos homens de tal modo que eduque o mais possível de modo humano, conclui Marx" (1976, p. 162).

Porém, como na forma social do capital, "capitalistas e trabalhadores são, uns e outros, subsumidos pela classe, membros de uma classe e não-indivíduos (MANACORDA, 2007, p. 80), a educação enquanto produto desta forma social é uma educação de classe. Não é o resultado da ação do meio, como apregoam os reacionários do sensualismo, mas da luta de classe. Assim, enquanto trabalho social a educação não está isenta do enfrentamento, da luta de classe, aliás, é na luta que ela acontece.

Por isso consideramos essencial enfatizar aqui que as possibilidades da educação enquanto processo de humanização não estão na "educação em si", mas no processo de articulação com o trabalho, isto é, na articulação entre teoria e prática, ou seja, na práxis histórica, como mencionamos anteriormente. Desse modo, entendemos que o acesso à educação é fundamental para a classe trabalhadora, porém insuficiente se ficarmos nos limites da sociedade capitalista, cujo ideário educacional tem sido sinônimo de: modelamento, disciplinarização, treinamento, profissionalização e docilização dos indivíduos. Ou seja, para a burguesia as pessoas precisam aprender a adaptar-se dentro deste modo de produção e não transformá-lo; assim, se no feudalismo quem ensinou foi a Igreja, no capitalismo esta tarefa passa a ser da escola. Cabe à escola ensinar a viver na "pós-modernidade", isto é, ensinar a ser habilidoso, competente e flexível para viver empregado e desempregado, para ser capaz de adequar-se à precarização dos empregos, para fazer trabalho informal, mesmo sendo formado. Cabe a escola ensinar a ser profissional, isto é, transformar o indivíduo num empresário de si mesmo, num 
empreendedor, expressão extrema da lógica de produção e reprodução do capital, onde a proliferação de igrejas e o aquecimento do mercado da literatura de auto-ajuda é mera coincidência ou não!? Neste caso, em vez de educação como processo de humanização, estamos diante de uma verdadeira utopia educacional. Nesta perspectiva, para ficar apenas com os clássicos podemos citar, como exemplo Saint Simon (2002), que via na educação a solução para os problemas sociais através do progresso das ciências, ou Fourier (2002), que propõe uma educação harmônica, como meio de resolver os problemas sociais, ou ainda Owen (2002), que propõe uma reforma moral da sociedade pela educação como alternativa para os problemas sociais.

É no Capital que Marx vai nos oferecer os elementos essenciais para pensar a educação para além das utopias. Depois de analisar a teoria do valor e a mais-valia, Marx vai analisar a revolução operada pelo capitalismo no modo de produção - concentração, cooperação, divisão do trabalho, maquinaria - e os resultados de tudo isso sobre a situação dos trabalhadores na indústria. Analisa também a questão do trabalho das mulheres e das crianças. Nesta análise descobre, por exemplo, que contraditoriamente o capital se vê obrigado a lançar mão da educação. Assim, se a educação no conjunto das ações empreendidas socialmente constitui-se como um elemento importante no processo de transformação social, vai constituir-se também como um elemento não menos importante no processo de desenvolvimento da sociedade capitalista. Daí a necessidade de estarmos atentos a esta dimensão da educação que é funcional ao capital. Marx apresenta os elementos para a análise desse aspecto quando examina no desenvolvimento da maquinaria, a questão da legislação fabril inglesa e suas disposições relativas à higiene e à educação. Diz Marx, a legislação fabril é "a primeira reação consciente e metódica da sociedade contra a forma espontaneamente desenvolvida de sua produção" (MARX, 2008, p. 545). E ampliando a sua análise acrescenta: "Apesar das aparências mesquinhas que apresentam em seu conjunto as disposições da lei fabril relativas à educação fizeram da instrução primária condição indispensável para o emprego das crianças" (MARX, 2008, p. 547). Mas não é só isso que Marx acaba descobrindo em sua investigação. Para além da educação obrigatória - estamos falando de lei fabril - é preciso explorar a possibilidade que tal educação oferece. E que possibilidade é essa? É a escola de meio período cujo êxito Marx assim sintetizou: "Seu sucesso demonstrou, antes de tudo, a possibilidade de conjugar educação e ginástica com trabalho manual e, consequentemente, o trabalho manual com educação e ginástica" (MARX, 2008, p. 547). Aqui está no nosso entender a origem da alternância trabalho-educação. Ampliando a sua análise, Marx vai mostrar as vantagens - para o capital - desse sistema de alternância que tem na fábrica o projeto de educação do futuro assim configurado:

Do sistema fabril [...] brotou o germe da educação do futuro, que conjugará o trabalho produtivo de todos os meninos além de uma certa idade com o ensino e a ginástica, constituindo-se em método de elevar a produção social e em único meio de produzir seres humanos plenamente desenvolvidos ( MARX, 2008, p. 548-549).

Neste caso, desenvolvidos para o capital. E na Crítica ao Programa de Gotha, Marx acentua esta contradição que está posta pelo sistema de educação - a alternância que surge com a lei fabril no contexto da revolução industrial, ao demonstrar que:

A proibição geral do trabalho infantil é incompatível com a existência da grande indústria e, portanto, um piedoso desejo, porem nada mais. Pôr em pratica esta proibição - supondo-a factível - seria reacionário, uma vez 
que regulamentada severamente a jornada de trabalho segundo as diferentes idades e aplicando as demais medidas preventivas para a proteção das crianças, a combinação do trabalho produtivo com o ensino, desde uma tenra idade, é um dos mais poderosos meios de transformação da sociedade atual (MARX, 2005, p. 242).

Feita esta observação, é possível delimitar objetivamente os limites e possibilidades do sistema de alternância que surge como expressão da divisão do trabalho no contexto da revolução industrial. Pois, a análise de Marx mostra que a mesma lei que cria a alternância como espaço de educação que visa preparar o indivíduo para o trabalho fabril, acaba também universalizando a obrigatoriedade da escola. Temos, assim, a superação da oposição escola e não-escola - oposição que é historicamente contextual ao período préindustrial - para o surgimento da oposição escola e escola, ou seja, continuamos a ter escola para as classes possuidoras - para usar uma expressão de Manacorda - e agora também escola para as classes despossuídas. Grosso modo, a escola pública, laica e gratuita, nasce capitalista, tendo como princípio básico, a alternância entre ensino e trabalho. Por isso, discutir escola a partir da revolução industrial é discutir escola capitalista. A idéia de alternância aparece neste processo como uma idéia essencialmente capitalista, funcional ao capital neste momento e contexto histórico. Constitui-se historicamente como categoria universal, isto é, uma categoria capitalista, por isso, essencialmente conservadora.

Para compreender o sentido desse processo de universalização, isto é, o sentido da escola capitalista para as classes despossuídas é preciso considerar também que a revolução industrial vai produzir mudanças não só no modo de produzir, mas também no modo de pensar, isto é, na consciência. Como em Marx atividade implica ação com um grau de consciência, a consciência depende do ser social, neste sentido não é algo dado, é processo, é movimento. Como explica Iasi em seu livro Ensaios Sobre Consciência e Emancipação: "sabemos que só é possível conhecer algo se o inserirmos na história de sua formação, ou seja, no processo pelo qual ele se tornou o que é; assim é também com a consciência: ela não "é”, "se torna” (IASI, 2007, p.12). E Manacorda acrescenta:
É uma maturação de consciência que não se compreende se não se leva em conta o desenvolvimento do real com a revolução industrial, que não somente efetua o encontro entre artes liberais e mecânicas, entre geometria intelectual e experimental, mas subtrai o homem em crescimento, o adolescente, da angústia familiar e corporativa e joga-o no mais vasto mundo social. O nascimento da escola pública é contextual ao da fábrica e comporta as grandes mudanças na vida social dos indivíduos (MANACORDA, 2007, p. 358).

A burguesia não pode criar nada que não valorize o valor. Inclusive o próprio trabalho se torna para a burguesia valor, neste caso, valor-de-troca. Portanto, se a escola é uma criação burguesa, logo, é inevitável perguntar: que escola é esta? Que possibilidades educativas emergem neste processo social de base industrial-capitalista? Quais os limites e possibilidades da alternância ${ }^{2}$ neste contexto, uma vez que "foi nesse nível metodológicohistórico que se pôde produzir a separação entre a escola do doutor e a escola do trabalhador: a primeira acentuadamente livresca e desinteressada; a segunda acentuadamente profissional e prática; mas ambas, definitivamente escolas" (MANACORDA, 2007, p. 124). Entendemos assim a alternância como uma categoria constitutiva e contextual à escola capitalista, que expressa a concepção de prática inerente à escola a partir da divisão do trabalho, da maquinaria e grande indústria. De fato, 
etimologicamente, alternância significa "alternar + anciã, prov. Sob o influxo do Francês alternance (1830); alter, filosofia da história, (1871) Alternância: que deriva de alter, antepositivo, do latim. Alter, a, um; um outro, diferente, oposto, contrário" (DICIONÁRIO HOUAISS DA LÍNGUA PORTUGUESA, 2001, p. 168). Ou seja, alternar não significa relacionar, articular, mas opor, diferenciar. Não há no processo de alternar um movimento que permita, por exemplo, articular teoria e prática, trabalho e educação, isto é, não se trata de relação, mas da oposição ora um ora outro. Alternar é fragmentar. Aliás, a fragmentação é justamente, como vimos acima, o processo que se consolidou com a divisão do trabalho, maquinaria e grande indústria. A alternância configura-se assim na esfera da lógica formal, ou um ou outro. Não há um intercâmbio entre as partes, por isso, não se pode falar de atividade criadora, de práxis histórica, na esfera da alternância. A atividade que acontece na alternância é uma atividade dual e restrita ao particular, a coisa em si. Não é uma atividade mediadora. Nega-se assim a perspectiva da totalidade, isto é, da relação entre universal, particular e singular. Relação fundamental na perspectiva dialética, pois "a universalidade sempre existe em relação à particularidade: não é possível separá-las, ainda que constituam momentos distintivos de nossas operações conceituais e nossos engajamentos práticos" (HARVEY, 2006, p. 316). Logo, teoricamente, não se pode falar em atividade real e concreta na esfera da alternância, pois o dualismo impede que se considere a contradição ao não propiciar a articulação dos termos contrários, como momentos constitutivos da unidade.

Entendemos que os elementos aqui discutidos permitem conceber a educação enquanto processo histórico e social que articulada ao trabalho ajuda a apreender a conexão entre escola e vida, na perspectiva da transformação e não da reprodução social. Tal apreensão é fundamental para superar a dicotomia entre teoria e prática, enfatizando sempre que:

A prática que Marx tem em mente é algo que não coincide com o objetivo individual em que se verifica a validade de um pensamento, que é a posição característica de um certo pragmatismo. Marx fala, no entanto, de modificar o mundo, isto é, de uma atividade na qual a sociedade humana está fortemente empenhada e que representa, de certa maneira, todo o processo de sua história: apropriar-se da natureza de modo universal, consciente e voluntário, modificá-la e ao modificar a natureza e seu próprio comportamento em relação a ela, modificar a si próprio, como homem (MANACORDA, 2007, p. 128).

É nesta perspectiva que defendemos a necessidade de se discutir a articulação entre trabalho e educação.

\section{A Pedagogia da Alternância}

A pedagogia constitui-se num dos espaços importantes para se estabelecer a conexão entre trabalho e educação. Pedagogia que:

$\mathrm{Na}$ sua origem significou prática ou profissão de educador, passou depois a designar qualquer teoria da educação, entendendo-se por teoria não só uma elaboração organizada e genérica das modalidades e possibilidades da educação, mas também uma reflexão ocasional ou um pressuposto qualquer da prática educacional (ABBAGNANO, 2007, p.871). 
Todavia, com o passar do tempo, deixou de ser uma simples reflexão e passou a ser uma forma de organizar os fins e meios da educação. Esta sistematização de forma científica deve-se "a Herbart que organizou os fins da educação (que a Pedagogia deve haurir da ética) e os meios educacionais (que a Pedagogia deve haurir da psicologia), procurando elaborar, distinta e correlativamente, essas duas partes" (ABBAGNANO, 2007, p.871). Com efeito, diz Saviani, "o adjetivo "pedagógico" tem marcadamente ressonância metodológica denotando o modo de operar, de realizar o ato educativo" (SAVIANI, 2008, p. 6), ou seja, o ato pedagógico é o espaço onde se constitui e expressa a articulação entre trabalho e educação, teoria e prática, isto é, a práxis histórica. Entretanto, pode-se dizer que, a clássica sistematização da pedagogia deve-se a SUCHODOLSKI (2002) que com base nas grandes correntes do pensamento filosófico vai demonstrar que se constituíram ao longo da história duas tendências pedagógicas fundamentais, uma pedagogia baseada na essência do homem e outra pedagogia baseada na existência. Assim situadas historicamente as tendências pedagógicas podem "contribuir para a compreensão de um fato histórico, a saber: que as posições pedagógicas defendidas nunca foram homogêneas; no entanto, quer pela genealogia, quer pelas suas repercussões, revelam sempre numerosos elementos de contatos" (SUCHODOLSKI, 2002, p.11). Nesta perspectiva, entendemos que a Pedagogia da Alternância expressa tanto na sua origem quanto em seu desenvolvimento e resultados uma tendência contemporânea que é a emergência de varias formas de sistematizar a educação em geral e a do campo em particular. Cite-se como exemplo desta tendência a Pedagogia do oprimido ${ }^{3}$, Pedagogia da terra ${ }^{4}$, Pedagogia do Movimento Sem-Terra ${ }^{5}$, entre outras.

De acordo com Gimonet ${ }^{6}$, o processo de constituição e sistematização da Pedagogia da Alternância - que passaremos a analisar a partir de agora - apresenta na sua origem

O movimento de ação social Le Sillon, de Marc Sangnier, e depois o pensamento de um grande filósofo personalista, Emmanuel Mounier, a metodologia do "Ver - Julgar - Agir" deste grande e bonito movimento de educação popular, a "JAC"7, mas também o espírito e os procedimentos da educação nova e de outros pensadores e pedagogos servem como referências ou prestam sua contribuição (GIMONET, 2007, p. 23).

No seu desenvolvimento e consolidação é possível também,

Notar os empréstimos, antes de tudo, das correntes da pedagogia ativa com Decroly e seu método dos "centros de interesse", R. Cousinet e o trabalho livre em grupos, J. Dewey e a relação entre experiência e educação, C. Freinet e o texto livre ou a biblioteca de trabalho, M. Montessori, mas, também, as orientações de Steiner, da Escola Alsaciana... Depois, mais tarde, os aportes de J. Piaget, como indicado anteriormente, C. Rogers, B. Schwartz.... mas, também, P. Freire e A Educação como prática da liberdade, pelos seus métodos de alfabetização ( GIMONET, 2007. p. 23-24).

Portanto, um dos princípios filosóficos que fundamenta a Pedagogia da Alternância é o personalismo ${ }^{8}$ de Emmanuel Mounier, entre outros. Na introdução do livro que reúne as contribuições dos participantes do primeiro seminário internacional de Alternância realizado em Salvador (Bahia), em novembro de 1999, Pedro Puig Calvo, diretor técnico da SIMFR", assim expressou a opção pelo personalismo: "O personalismo é uma corrente humanista que surge em oposição ao comunismo coletivista das pessoas e do capitalismo liberal onde as pessoas constituem igualmente instrumentos utilizados para enriquecer-se" 
(CALVÓ, 1999, 23). Esta opção pelo personalismo nos permite situar a Pedagogia da Alternância no arcabouço teórico-filosófico do idealismo.

Pode-se afirmar, de modo geral, que a concepção idealista do homem se manifesta de duas formas básicas: a primeira e mais antiga escolheu como ponto de partida a análise da chamada essência humana, enquanto que a segunda, que só adquiriu importância a partir do século XIX, partiu da análise da chamada existência humana (SUCHODOLSKI, 1976, p. 148).

Assim, com base num ideal abstrato de ser humano, a Pedagogia da Alternância constitui-se enquanto forma de sistematização de um projeto de educação para o jovem do campo a partir de quatro finalidades: orientação, adaptação ao emprego, qualificação profissional e formação geral; elegendo como meio para alcançar estas finalidades a alternância e a associação entre famílias, professores, monitores e instituição.

Quanto às finalidades, Gimonet vai caracterizá-las da seguinte forma:

a) orientação: a alternância aparece como um meio de orientação profissional e de subsídio na determinação de um projeto realista de inserção profissional [...]; b) adaptação ao emprego: a alternância tornase, neste caso, um meio para suprir a inadequação entre a formação e o emprego. [...]; c) qualificação profissional: dois modos se opõe para a formação e qualificação profissional: a aprendizagem com o domínio da formação prática dada no seio das empresas; a formação escolar onde prevalece a formação teórica. Aí, entre o "todo empresa" ou o "todo escola", a alternância aparece como o meio apropriado para ligar os dois em vez de confrontá-los. E, enfim, parece entender-se que uma profissão não se aprende no quadro negro com giz! A alternância constitui o meio, ao mesmo tempo, para aceder a uma qualificação reconhecida por diploma e de construir uma identidade profissional duradoura; d) formação geral: [...] uma outra finalidade, mais ampla, só está sendo raramente exposta: a da formação geral, da formação global da pessoa. Trata-se, através da alternância, de trabalhar os mesmos programas, de preparar para os mesmos exames, de permitir o acesso ao prosseguimento dos mesmos estudos que através do ensino tradicional (GIMONET, 2007, p. 119).

A caracterização destas finalidades nos oferece os elementos essenciais para delimitar a perspectiva da Pedagogia da Alternância. Quanto à formação geral, a que se propõe parece configurar-se nos limites da lógica do capital, cuja tendência é a precarização de tudo, como vimos acima. Entendemos que tal precarização acontece, por exemplo, a partir do momento que são propostos os mesmos programas e o desafio de preparar para os mesmos exames e permitir o acesso e prosseguimento dos mesmos estudos que a escola regular, porém em menos tempo. Em menos tempo, porque o aluno fica uma semana em casa trabalhando e outra na escola estudando. Já na escola regular, o aluno está presente na escola todos os dias. Em tese, o aluno da escola regular teria mais tempo de escola e menos de trabalho. Embora, quando se trata de escola para os despossuídos, o capital busca sempre organizá-la tendo em vista a reprodução social e, neste caso, predomina a lógica da valorização do valor. Por isso, essas formas de organizar a escola acabam na maioria das vezes mascarando o problema do trabalho infantil, isto é, acabam adequando o ensino à exploração da força de trabalho. 
Especificamente, em relação à formação geral, entendemos que as finalidades a que se propõe a Pedagogia da Alternância acabam induzindo esta formação no sentido de reforçar a idéia de que é possível produzir a vida na sociedade capitalista, inclusive na pequena propriedade, bastando para isso ser um profissional. Não há assim espaço para a crítica das relações capitalistas de produção, muito menos para discutir uma alternativa para além do capital, como afirma Mészáros (2002).

Estas finalidades expressam as contradições e os limites deste projeto de educação para o jovem do campo: $1^{\circ}$ ) porque é preciso ser proprietário. Como uma boa parte das famílias que moram no campo não são proprietárias, em tese seus filhos não poderiam frequientar a escola por alternância; $2^{\circ}$ ) porque o ideal perseguido nesta é a permanência do jovem junto à família no campo, como se este ainda fosse o espaço não contaminado pelos problemas da cidade, como por exemplo, drogas, alcoolismo, violência, desemprego; $3^{\circ}$ ) porque busca a transformação da pequena propriedade em empresa capitalista, portanto, é a consolidação da revolução burguesa no campo; $4^{\circ}$ ) porque na semana que o alternante ${ }^{10}$ fica em casa, ele tem que trabalhar na propriedade que funcionaria como uma espécie de laboratório, para testar os conhecimentos adquiridos na semana que ficou na escola, caso contrário não se justificaria ficar uma semana em casa; $5^{\circ}$ ) porque num país que predomina o grande latifúndio, vem "iludir" quem tem uma propriedade pequena, fazendo-o acreditar que é possível produzir a existência na pequena propriedade bastando para isso transformála numa pequena empresa; ledo engano, em uma época que as médias e grandes empresas estão se fundindo para sobreviver à concorrência infernal imposta pelo capital mundializado.

Estas contradições e limites revelam que a Pedagogia da Alternância oscila entre a pedagogia da essência do homem e a pedagogia da existência, uma vez que:

A primeira encontra a sua determinação na pedagogia humanista. À margem da vida, procura os ideais eternos de perfeição. É verdadeiramente alheia à realidade e destaca o caráter de elite da educação [...]. A segunda elabora-se na pedagogia do "lucro e da utilidade". Sente-se interessada pela utilização do saber imediato e das máximas adequadas à vida e esforça-se pela formação de capacidades para a criação de bens materiais e para o desempenho de ofícios, especialmente dos "ofícios crematísticos" (SUCHODOLSKI, 1976, p. 136).

Enfatize-se aqui que as contradições e limites desta concepção pedagógica não está no fato de oscilar entre uma tendência e outra, mas no fato de que tanto a pedagogia da essência quanto a pedagogia da existência estão configuradas nos limites da educação liberal.

Da mesma forma que não existe uma via de acesso da pedagogia da existência ao ideal, nenhum caminho liga a pedagogia da essência à vida [...] nenhuma delas concebe o homem concreto e vivo, um homem "em carne e osso", pertencendo a um lugar definido e a uma época determinada da história. Uma reduz o homem às proporções de receptáculo e veículo de valores culturais, a outra concebe-o como uma experiência contemplativa ou uma emoção mística. Em ambos os casos, a educação incidia num domínio limitado da vida humana e não tinha qualquer relação nem com a atividade real, social e profissional do homem, nem mesmo com a totalidade da sua vida individual (SUCHODOLSKI, 2002, p. 95-96). 
Observamos, também, que as contradições se acentuam no que diz respeito aos meios adotados pela Pedagogia da Alternância para a concretização das finalidades a que se propõe. Uma vez que, nesta perspectiva, "coloca-se para o alternante uma dupla relação: ao trabalho e ao mundo da produção e seus saberes, à vida social e econômica, ambiental e cultural dos lugares onde vive, de um lado; a um lugar "escolar" com suas atividades, sua cultura e seus saberes de outro lado" (GIMONET, 2007, p. 29). Outro aspecto relevante é que a Pedagogia da Alternância - que postula o desenvolvimento do meio e não sua transformação - propõe dividir com os pais a tarefa educativa. Por isso, diz Gimonet: "não é mais um aluno na escola, mas já um ator num determinado contexto de vida e num território. Sua família é convidada a participar ativamente de sua educação, de sua formação, acima de tudo porque é jovem" (GIMONET, 2007, p. 19). A ênfase na importância da família e da profissionalização foi reafirmada no VIII Congresso Internacional realizado em maio de 2005 nas cidades de Foz do Iguaçu (Brasil) e Puerto Iguazú (Argentina), quando se elaborou um documento que ficou conhecido como Manifesto de Iguaçu, contendo dez itens, dos quais destacamos aqui o primeiro e o oitavo, para ilustrar esta importância no contexto da Pedagogia da Alternância.

$1^{\circ}$. Sendo a família a primeira educadora, respeitar o seu direito à liberdade de educar seus filhos de forma apropriada ao meio rural, de acordo com sua própria realidade, respeitando a cultura, crenças, idiossincrasias e as expectativas de melhorar a qualidade de vida [...] $8^{\circ}$. Garantir os apoios técnicos e financeiros necessários que permitam aos jovens do meio rural, apropriadamente formados, serem atores do desenvolvimento local, como empreendedores de seus Projetos Profissionais (ANAIS DO $8^{\circ}$ CONGRESSO INTERNACIONAL, 2005, p. 144-145).

Portanto, transfere-se para a família a responsabilidade do Estado, ao direcionar a formação para a profissionalização e permanência do jovem na propriedade. Esta pedagogia se parece mais com uma assessoria empresarial, ao melhor estilo SENAI, do que um projeto de educação para o jovem do campo. Bastaria o jovem ser profissional, isto é, um empreendedor para tornar a propriedade viável e a vida no campo o lugar ideal para se viver. Ou seja, basta à educação cumprir a função de adequar o alternante às novas exigências da empresa e do mercado e despertar nele o espírito empreendedor.

Por isso, o instrumento que juntava o conjunto das observações, análises e reflexões e estava sendo construído ao longo da formação, foi chamado de "caderno da exploração familiar". Para as meninas, o processo similar para as atividades domésticas recebeu o nome de "caderno de casa". Em seguida, a mesma caminhada foi seguida pelas Maisons Familiales Rurales (Casas Familiares Rurais) que foram abertas no setor de artesanato, nascendo assim o "caderno da empresa" (GIMONET, 2007, p. 32).

Estes cadernos são considerados como um elemento singular no processo de formação por se tratar de "um instrumento de trabalho para que os jovens sejam atores de sua formação e aprendam a aprender" (GIMONET, 2007, p. 52). Salientamos aqui que o lema do "aprender a aprender" parece expressar a principal tendência da Pedagogia da Alternância. Neste sentido, a compreensão da lógica subjacente a esta forma de sistematizar a educação do campo passa, inevitavelmente, pela apreensão critica do sentido deste lema, pois, de acordo com Duarte, 
O "aprender a aprender" significa educar indivíduos adequados à dinâmica do capitalismo. Não se trata de superar o capitalismo, não se confunda mudança com revolução, com transformações radicais nas relações de produção. As mudanças fazem parte do processo dinâmico de reprodução da sociedade capitalista. Neste sentido, o discurso da mudança, perfeitamente afinado com o "aprender a aprender", nada tem de crítico e sim, pelo contrário, encontra-se a serviço da adaptação dos indivíduos às exigências econômicas, políticas e culturais do capitalismo contemporâneo (DUARTE, 2006, p.156)

Desta forma, a formação em curso na Pedagogia da Alternância, a partir do "aprender a aprender", caracteriza-se como uma formação unilateral, com ênfase na profissionalização. Portanto, não está em questão nesta pedagogia a formação omnilateral e a possibilidade de emancipação humana.

Toda a alternância reside naquilo que coloca o alternante em jogos de complexidade, de passagens, de rupturas e de relações. Ele encontra e vive entidades diferentes, cada uma com sua especificidade, seus saberes, seu saber-fazer e saber-ser, sua linguagem, sua cultura, seus atores, seus jogos de influência nos quais o "eu", numa dialética de personalização e socialização deve situar-se, construir-se e crescer (GIMONET, 2007, p. $68)$.

Em síntese, pode-se dizer que "introduzir a alternância para a formação significa diversificar os espaços e os tempos para aprender, se formar, se orientar. É substituir uma pedagogia plana por outra no espaço e no tempo. É ingressar na complexidade e na educação sistêmica"11 ( GIMONET, 2007, p. 81).

Por conta dos ideais e objetivos que propõe aos jovens do campo, bem como do modo específico de alcançá-los - a alternância e a associação entre professores, monitores e instituição, esta pedagogia apresenta-se para aqueles que a adotam como um sistema pedagógico novo:

Novo porque derruba os muros da escola para utilizar os saberes e suportes de aprendizagem da vida. Novo porque o alternante não é mais um aluno na escola que consome passivamente saberes de um programa, mas um ator socioprofissional que constrói sua formação. Novo porque os pais bem como os mestres de estágios, tornam-se parceiros coformadores. Novo porque o dispositivo pedagógico compreende uma variedade de atividades e de instrumentos apropriados ao processo de alternância. Novo porque o Centro Familiar de Formação por Alternância (CEFFA) não é somente um espaço de ensino mas uma estrutura de vida educativa. Novo porque os monitores não são docentes tradicionais, mas animadores de formação, generalistas, mais do que especialistas disciplinares, na escuta dos saberes do meio vivencial e dos alternantes como daqueles dos programas acadêmicos. Novo, ainda, porque a vida dos Centros Familiares de Formação por Alternância (CEFFAs), suas orientações e sua política de formação se coloca sob a responsabilidade da associação dos pais, dos responsáveis profissionais e de outras pessoas interessadas pelo projeto dos Centros Familiares de Formação por Alternância (CEFFAs). Novo, enfim, porque a ambição reside, através da educação dos adolescentes, em contribuir com as evoluções e desenvolvimentos dos territórios (GIMONENT, 2007, p.99). 
Como diz Duarte, "sem meias-palavras, consideramos que tudo isso não passa de uma forma eufemística de aceitar, sem questionamentos, o cotidiano alienado e fetichizado" (DUARTE, 2006, p. 55) do que seja hoje o campo em geral e o brasileiro em particular.

De acordo com Gimonet (2007), este estatuto teórico permite propor a Pedagogia da Alternância como projeto de educação para o campo, assim denominado: Um CaminhoMétodo Para o Amanhã e a Era Planetária, ou seja, para os defensores desta pedagogia:

A "plenitude de sentido" do movimento das MFR12 encontrar-se-á na ótica personalista e humanista de sua ação, mais inscrita na corrente da educação planetária, da educação para a cidadania universal, de "uma pedagogia da terra", de uma "ecopedagogia" de que já se fala muito no planeta, particularmente na América Latina (GIMONET, 2007, p.157).

Qualquer semelhança com os quatro pilares fundamentais da educação, que constam do relatório da UNESCO sobre a educação para o século XXI, elaborados por Jacques Delors (1998), a saber: "aprender a conhecer", "aprender a fazer", “aprender a ser" e "aprender a conviver", não é mera coincidência.

\section{Considerações Finais}

Concluímos que a educação na Pedagogia da Alternância no contexto da relação capital-trabalho, aparece como meio para "qualificar" e "requalificar" com isso ampliar a produção da mais-valia.

Porém, como a nossa perspectiva teórico-filosófica é outra, defendemos um projeto de educação que não se enquadre e aceite o estado de coisas existente, ou seja, "uma pedagogia associada a uma atividade social que transforme o estado de coisas que tenda a criar no homem condições tais que a sua existência se possa tornar fonte e matéria-prima da sua essência" (SUCHODOLSKI, 1976, p. 101). Com isso estamos indicando que:

$\mathrm{O}$ homem não se forma nem exclusivamente sob a influência das condições do ambiente, nem apenas sob a influência da sua consciência, nem, finalmente, sob a influência de certa combinação de ambos os fatores. O elemento decisivo no processo de formação do homem é a atividade sócio produtiva do homem que transforma o seu ambiente" (SUCHODOLSKI, 1976, p. 62).

Assim, se de fato o primeiro pressuposto de toda a existência humana e de toda a história é que os homens devem estar em condições de viver para poder fazer história, como indicaram Marx e Engels (2007) na Ideologia Alemã, um projeto de educação para a classe trabalhadora, seja ela do campo ou da cidade, não pode prescindir deste pressuposto. Ou seja, a educação não pode ser um apêndice das demandas do mercado. Por isso, no nosso entendimento, um projeto de Educação Virada Para o Futuro fundamenta-se no trabalho enquanto atividade criadora e constitutiva do ser humano articulado à educação. Esta articulação é essencial para organizar a escola na perspectiva da transformação social e da emancipação humana. Como "é necessário romper com a lógica do capital se quisermos contemplar a criação de uma alternativa significativamente diferente" (MÉSZÁROS, 2005, p. 27), não basta que o trabalho entre na escola, que se alterne trabalho e ensino. É preciso muito mais que isso. É preciso que o trabalho e a educação sejam a expressão de um projeto estratégico de transformação social. Que o trabalho para além da mediação entre o homem e a natureza seja também uma forma de mediação com a atualidade dos alunos. Assim, o trabalho articulado com a educação provoca a ruptura ao 
fazer com que a escola se relacione com a vida e não com o capital como vem acontecendo com a escola capitalista em geral e a pedagogia da alternância em particular.

Referências Bibliográfias

ABBAGNANO, N. Dicionário de filosofia. São Paulo: Martins Fontes, 2007.

BRAVERMAN, H. Trabalho e capital monopolista, a degradação do trabalho no Séc. XX. Rio de Janeiro: LTC editora, 1987.

CALDART, R. Pedagogia do movimento sem terra. Petrópolis: Vozes, 2000.

CONGRESSO INTERNACIONAL, FAMILIA, ALTERNÂNCIA E

DESENVOLVIMENTO, Anais... Foz do Iguaçu - Puerto Iguazú. 2005, p. 144-145.

CALVÓ, P. P. Centro familiares de formação em alternância. In. Sommerman, A. (org.) Pedagogia da alternância - alternância e desenvolvimento. Salvador: Unefab, 1999.

DELORS, J. (Org.) Educação um tesouro a descobrir. São Paulo: Cortez/Brasília: MEC: UNESCO, 1998.

DUARTE, N. Vigotski e o "aprender a aprender" crítica às apropriações neoliberais e pós-modernas da teoria vigotskiana. 4ed. Campinas: Autores associados, 2006.

FREIRE, P. Pedagogia do oprimido. São Paulo: Vozes, 2000.

FOURIER, C. O Novo mundo industrial e societário. In. TEIXEIRA, A. Utópicos, heréticos e malditos; os precursores do pensamento social de nossa época. Rio de Janeiro: Record, 2002.

GADOTTI, M. Pedagogia da terra. São Paulo: Vozes, 2000.

GIMONET, J. C. Nascimento e desenvolvimento de um movimento educativo: as casas familiares rurais de educação e orientação. In: I Seminário internacional da pedagogia da alternância: alternância e desenvolvimento. Anais... Salvador: UNEFAB, 1999, p.39-48.

Praticar e compreender a pedagogia da alternância dos CEFFAs. São Paulo: Vozes, 2007.

HARVEY, D. Condição pós-moderna. 15 ed. São Paulo: Loyola, 2006.

HOUAISS, A. VILLAR, M. S. FRANCO, F. M. M. Dicionário houaiss da língua portuguesa. Rio de Janeiro: Objetiva, 2001.

IASI, L. M. Ensaios sobre consciência e emancipação. São Paulo: Expressão Popular; 2007.

MANACORDA, A. M. Marx e a pedagogia moderna. 2 ed. São Paulo: Alínea, 2007. 
MARX, K. Critica da Filosofia do direito de Hegel. São Paulo: Boitempo, 2005.

O Capital. V. 1, Rio de Janeiro: Civilização Brasileira, 2008.

MARX, K. ENGELS, F. A Ideologia alemã. São Paulo: Boitempo, 2007.

Manifesto comunista. São Paulo: Boitempo, 2007.

MÉSZÁROS, István. Para além do capital. São Paulo: Boitempo, 2002.

A Educação para além do capital. São Paulo: Boitempo, 2005.

A Teoria da alienação em marx. São Paulo: Boitempo, 2006.

O Desafio e o fardo do tempo histórico. São Paulo: Boitempo, 2007.

OWEN, R. O Livro do novo mundo moral. In. TEIXEIRA, A. Utópicos, heréticos e malditos; os precursores do pensamento social de nossa época. Rio de Janeiro: Record, 2002.

SAVIANI, D. História das idéias pedagógicas no Brasil. Campinas: Autores Associados, 2008.

SIMON, H. S. Parábola. In. TEIXEIRA, A. Utópicos, heréticos e malditos; os precursores do pensamento social de nossa época. Rio de Janeiro: ed. Record, 2002.

SUCHODOLSKI, Bogdan. Teoria marxista da educação. V. III. Rio de Janeiro: Martins Fonte, 1976.

A pedagogia e as grandes correntes filosóficas: A pedagogia da essência e a pedagogia da existência. São Paulo: Centauro, 2002.

VÁZQUEZ, A. S. Filosofia da práxis. São Paulo: Expressão Popular, 2007.

Notas.

\footnotetext{
${ }^{1}$ Sobre o conceito de homem omnilateral, indicamos a leitura do capitulo três (p. 87- 94) da obra de Mario A. Manacorda, Marx e a pedagogia moderna, publicado pela Ed. Alínea, Campinas, 2007.

${ }^{2}$ Estamos nos referindo aqui à alternância que nasce com a obrigatoriedade do ensino no contexto da revolução industrial e não à Pedagogia da Alternância.

${ }^{3}$ FREIRE, P. Pedagogia do Oprimido. São Paulo, Ed. Vozes, 2000.

${ }^{4}$ GADOTTI, M. Pedagogia da Terra. São Paulo, Ed. Vozes, 2000.

${ }^{5}$ CALDART, R. Pedagogia do Movimento Sem Terra. Petrópolis, Ed. Vozes, 2000.

${ }^{6}$ Doutor em Ciências Sociais do Desenvolvimento e Ciências da Educação. Dedicou sua vida profissional à Pedagogia da Alternância no seio das Maisons Familiales Rurales (Casas Familiares Rurais) da França. Primeiro como monitor; depois, como diretor de uma delas, junto dos adolescentes rurais. Em seguida, como formador e diretor do Centro Pedagógico Nacional das MFR (CFR) da França, que prepara e qualifica o monitores e as monitoras. É autor de livros e trabalhos sobre a Pedagogia da Alternância. A principal obra
} 
traduzida para o português e publicado pela editora Vozes é Praticar e Compreender a Pedagogia da Alternância dos CEFFAs.

${ }^{7}$ JAC: Movimento da Juventude Agrícola Católica francesa.

${ }^{8} \mathrm{O}$ personalismo foi e é usado para designar três doutrinas diferentes, mas interligadas. A primeira é doutrina teológica, que afirma a personalidade de Deus como causa criadora do mundo, em oposição ao panteísmo que identifica Deus com o mundo [...] A segunda é uma doutrina metafísica, segundo a qual o mundo é constituído por uma totalidade de espíritos finitos que, em seu conjunto, constituem uma ordem ideal em que cada um deles conserva sua autonomia [...] A terceira é uma doutrina ético-política que enfatiza o valor absoluto da pessoa e seus laços de solidariedade com as outras pessoas em oposição ao coletivismo (que tende a ver na pessoa nada mais que uma unidade numérica), e ao individualismo (que tende a enfraquecer os laços de individualidade entre as pessoas). Foi com este sentido que Dühring empregou esse termo em Geschichte der National Okonomie (de 1899); com esse mesmo sentido, voltou a ser usado depois da Segunda Guerra Mundial por E. Mounier (Le personnalisme, 1950) e, na sua esteira, numerosos pensadores católicos, defensores do P. metafísico (ABBAGNANO, 2007, p. 882-883). Negrito nosso.

${ }^{9}$ Solidariedade Internacional dos Movimentos Familiares de Formação Rural.

${ }^{10}$ Os atores-chave do sistema, que se encontram no centro da aventura educativa: as pessoas em formação, adolescentes ou adultas. Não poderia defini-los pela palavra "aluno" porque o seu estatuto é diferente e se reporta demais ao sistema escolar do qual grande numero quis afastar-se. São atores socioprofissionais estudando, se formando, se educando em alternância, fazendo surgir a palavra "alternante" para designá-los (GIMONET, 2007, p.126). Negrito nosso.

${ }^{11}$ Tanto a noção de complexidade quanto a sistêmica, usadas por Gimonet, tem por base, segundo o próprio autor, a teoria da complexidade de Edgar Morin.

${ }^{12}$ Maisons Familiales Rurales (Casas Familiares Rurais).

${ }^{13}$ Em relação à questão da qualificação e requalificação do trabalhador indicamos a leitura do Livro Trabalho e Capital Monopolista: a degradação do trabalho no séc. XX de HARRY BRAVERMAN, Ed. LTC, 1987.

Recebido em: $\quad 16 / 11 / 10$

Aprovado em: $\quad$ 09/01/11 